ФГБНУ «ЯКУТСКИЙ НАУЧНО-ИССЛЕДОВАТЕЛЬСКИЙ ИНСТИТУТ СЕЛЬСКОГО ХОЗЯЙСТВА ИМ. М.Г. САФРОНОВА»

\author{
Л.М. Коколова \\ Л.Ю. Гаврильева \\ И.И. Григорьев
}

\title{
МЕТОДИКА ПРИМЕНЕНИЕ АЛЬБЕНА С ПРИ ПАРАЗИТАРНЫХ БОЛЕЗНЯХ ДОМАШНИХ СЕВЕРНЫХ ОЛЕНЕЙ (Методическое пособие)
}


ББК 46.3:48.73я73

M54

\section{АВТОРЫ:}

Коколова Людмила Михайловна, доктор ветеринарных наук, зав. лабораторией гельминтологии

Гаврильева Любовь Юрьевна, кандидат ветеринарных наук, младший научный сотрудник лаборатории гельминтологии

Григорьев Иннокентий Иннокентьевич, аспирант лаборатории гельминтологии

ФГБНУ «Якутский научно-исследовательский институт сельского хозяйства имени М.Г. Сафронова»

\section{РЕЦЕНЗЕНТ:}

Написанова Л.А., канд. биол. наук, старший научный сотрудник лаборатории иммунологии ФГБНУ «ВНИИП им Скрябина»

\section{ОТВЕТСТВЕННЫЙ РЕДАКТОР}

Коколова Людмила Михайловна, доктор ветеринарных наук, зав. лабораторией гельминтологии ФГБНУ «Якутский научноисследовательский институт сельского хозяйства имени М.Г. Сафронова»

Методика применение Альбена С при паразитарных болезнях M54 домашних северных оленей : методическое пособие / Л.М. Коколова, Л.Ю. Гаврильева, И.И.Григорьев ; Федер. гос. бюджет. науч. учреждение Якут. науч.-исслед. ин-т сел. хоз-ва им. М.Г. Сафронова. - Якутск, 2018. - 16 с.

\section{ISBN 978-5-6040039-5-4 \\ Агентство CIP НБР Саха}

Методическое пособие предназначено для специалистов оленеводческих хозяйств, ветеринарных и научных работников, студентов и аспирантов средних и высших учебных заведений факультетов ветеринарной медицины и биологии. Даны практические и методические рекомендации по борьбе, профилактике и лечении паразитарных болезней домашних северных оленей с применением эффективного антгельминтного препарата Альбен С.

Рассмотрено и одобрено на секции «Инвазионные болезни животных» ФГБНУ ВНИИП им. К.И. Скрябина (протокол №3 от 25.09.2014 г. Москва). 


\section{ВВЕДЕНИЕ}

Оленеводство является основой экономики и традиционного уклада жизни и основной производственной деятельностью коренных жителей горно-таежной зоны и важнейшей отраслью животноводства Республики Саха (Якутия), тесно связано с культурными традициями, образом жизни и экономическим благополучием коренных малочисленных народов Якутии. Горно-таежная зона является традиционным центром разведения домашних северных оленей, где сосредоточено около 1/3 часть поголовья оленей Якутии.

Дальнейшее развитие оленеводства, повышение продуктивности и рентабельности оленеводства невозможны без надежной организации и проведение эффективной меры защиты домашних северных оленей от различных болезней, в том числе гельминтозов и оводовых инвазий, которые причиняют значительный экономический ущерб в хозяйствах занимающихся разведением домашних северных оленей (Исаков, 1990; Коколова, 1995, 2013). Распространение гельминтозной инвазии у домашних северных оленей, наличие источников заражения с большим числом промежуточных и дополнительных хозяев, о зараженности гельминтами оленей, а также о мерах борьбы и профилактики паразитарных болезней и в своих работах в разные годы отметили Сафронов, 1960, 1975; Беляев, Назарова П.С., 1983; Губанов Н.И., 1964; Забродин, 1980; Исаков 1992; Коколова, 1995, 2013; Мицкевич В.Ю, 1967.

Исследование проблем распространения гельминтозов, разработка и внедрение совершенствованных методов комплексной профилактики и лечения является актуальной проблемой в условиях горно-таежной зоны Якутии. Сложившейся схемы разовых ветеринарных противопаразитарных обработок северных оленей, поиск высокоэффективных средств и способов применения против ассоциаций гельминтов, доступных и не затратных методов комплексного лечения гельминтозов северных оленей за счет применение эффективных антипаразитарных препаратов в сочетании с автохтонными растительно-минеральными и витаминно-пробиотическими добавками. 


\section{Химиотерапевтических исследований при ассоциативных инвазиях домашних северных оленей}

Для объективной оценки применяемых нами антгельминтных препаратов нам необходимо было определить эффективность препарата с последующей обработкой экстенсивности (ЭЭ) и интенсэкстенсивности (ИЭ), но и всестороннее изучение их антгельминтных свойств, поэтому нами разработана методика эффективности антгельминтных препаратов с учетом дифференцированного испытания препаратов против ассоциативных инвазий, с учетом различных стадий развития: имагинальная, преимагинальная и смешенная (преимагинально-имагинальная) дегельминтизации, химиопрофилактики и разработка комплекса оздоровительных мероприятий.

Перед нами стояла задача - изыскание эффективных антгельминтных препаратов для индивидуального и группового методах дегельминтизации, изучение эффективности используемых антгельминтных препаратов, испытание методики применения и разработки метода комплексного лечения в производственных условиях.

Изыскание эффективных препаратов для химиопрофилактики ассоциативных инвазий является наиболее трудным и сложным в исследованиях, поэтому исследование по химиопрофилактике разделили на три этапа: выявление профилактических свойств выбранных для применения антгельминтных препаратов, установление доз антгельминтиков при индивидуальном и групповом применении, определение химиопрофилактической эффективности в производственных условиях. Выбран препарат Альбен С.

Препарат Альбен С является эффективным комбинированным противогельминтным препаратом, составляющие компоненты празиквантел и альбендазол, обладают широким овоцидным спектром действия: активно действует против ленточных и 
круглых гельминтов на всех их стадиях развития снижает площадь заражения пастбищ яйцами гельминтов. Таблетка содержит 25 мг азинокса и 250 мг альбендозола.

Механизм действия препарата заключается в нарушении углеводного обмена и микротубулярной функции гельминтов, что приводит к гибели ивыведению их из организма оленей. Препарат активен в отношении половозрелых и неполовозрелых нематод и цестод, а также половозрелых трематод, снижает зараженность яйцами и личинками гельминтов пастбищ.

При разработке метода радикальной химиотерапии проводили исследования на $100 \%$ спонтанно зараженных оленей, выбрав в группах опыта по принципу аналогов подобрали одновозрастной молодняк оленей (1г 5мес.), на три группы по 5 голов 2 опытные группы и 1 контроль.

Первый опыт: разделили на I и II группу (опыт) и III группа (контроль) по 5 голов молодняка возрасте 1 г.5 мес. Определили ассоциации инвазий: мониезии, диктиокаулы, стронгилиды и трихоцефалы, котилофорон, личинки носоглоточного и подкожного овода. Применен препарат Альбен С.

Второй опыт разделили на I и II группу (опыт) и III группа (контроль) по 5 голов молодняка текущего года рождения. Определили ассоциации инвазий: мониезии, диктиокаулы, стронгилиды. Применен препарат Альбендазол 10\%, гранулят.

Tретий оnыm разделили на I и II группу (опыт) и III группа (контроль) по 5 голов молодняка текущего года рождения. Определили ассоциации инвазий: остертагии, мониезии, диктиокаулы, стронгилиды.

1 zруnпа подопытных оленей -5 голов препарат альбендазол $10 \%$ гранулят индивидуальное лечение в дозе 75 мг/кг массы животного;

2 zрупna 5 голов при групповом лечении препарат альбендозол $10 \%$ в дозе 50 мг/кг массы животного с концентрированным кормом из расчета 100 г корма на животное;

3 группа 5 голов - контроль лекарственный препарат не задан.

1 группа: 5 голов индивидуальная применение препарата, доза 3,75 г/100 живой массы;

2 группа 5 голов групповая дача препарата 3,75 г./100 живой массы; при групповом способе применения, рассчитанную дозу препарата смешиваем с концентрированным кормом из расчета корма на 1 животное 100 г., полученную смесь засыпаем в кор- 
мушки на группу 5 животных обеспечивали свободный доступ.

3 группа 5 голов - контроль концентрированный корм без антгельминтного препарат.

III опыт подопытных жсивотных 2 группы по 5 голов и 1 контрольная группа молодняка в возрасте 2-х лет определены по ассоциации инвазий: мониезиоз, диктиокаулез, стронгилез и трихоцефалез, котилофороноз, личинки носоглоточного и подкожного оводов. Применение препарата Альбен С:

1 группа: 5 голов индивидуальная применение препарата, доза 0,55 г/10кг живой массы животного;

2 группа 5 голов групповая дача препарата 0,55 г./10 массы животного; при групповом способе применения, рассчитанную дозу препарата смешиваем с концентрированным кормом из расчета корма на 1 животное 100 г., полученную смесь засыпаем в кормушки на группу 5 животных обеспечивали свободный доступ.

3 группа 5 голов - контроль задан концентрированный корм без антгельминтного препарат.

По данным гельминтологических вскрытий (через 28 дней после проведение химиотерапии) 9 голов, по 2 гол опытных и контрольных оставляем до забоя (ноябрь) нематодиреллез отмечали в 9,6 и 16,7\%, диктиокаулез - 2,4 и $1,3 \%$, стронгилез - 6,5 и 5,8\%, трихоцефалез - 14,3 и 5,7\%, нематодироз - 3,2 и $4,7 \%$, мониезиоз - 4,3 и 16,5\%, эзофагостомоз - 9,4 и 5,8\%, остертагеоз- 10,9 и 25,5\%, трихостронгилез - 5,6 и 16,2\%, котилофороноз, парамфитоматоз - 27,7 и 54,9\%, цистицеркозы паренхиматозный, тарандный - 1,3 и 5,1\% соответственно. Мониезиоз у молодняка оленей отмечен в $1,2 \%$, у взрослого поголовья мониезиоз не был обнаружен. Эхинококкоз у молодняка не были зарегистрированы, у взрослых оленей эхинококкоз отмечен в $0,5 \%$.

Полученные результаты вскрытий животных показывают, что больший процент зараженности животных отмечается при цистицеркозах до 32,6\%, наименьший при мониезиозе 0,5 $0,7 \%$.

Разработка и применение комплексного лечения паразитарных болезней домашних северных оленей

Исходя из изучения видового состава гельминтов домашних северных оленей горно-таежной зоны и установление паразитирования 31 вида гельминтов: 1 вид трематод Dicrocoelium lanceatum Stiles et Hassal, 1896; 4 вида цестод Taenia hydatigena 
(Pallas, 1766) - larvae; Echinococcus granulosus (Batsch, 1786) - larvae; Moniezia expansa (Rudolphi, 1810) Blanchard, 1891; Moniezia benedeni (Moniez, 1879) Blanchard, 1891 и 16 видов нематод Elaphostrongylus panticola Lubimov, 1945; Setaria altaica Rajewskaja, 1928; Varestrongylus sagittatus (Mueller,1891) Boev,1951; Dictyocaulus eckerti Skrjabin, 1931; Trichocephalus ovis Abildgaard, 1795; Trichocephalus skrjabini Baskakow, 1924; Nematodirus oiratianus Rajewskaja, 1929; Nematodirus spathiger (Railliet, 1896) Railliet et Henry, 1909; Oesophagostomum radiatum (Rudolphi, 1803) Railliet, 1898; Oesophagostomum venulosum (Rudolphi, 1809) Railliet et Henry, 1913; Ascworthius sidemi Schulz, 1933; Ascworthius gagarini Kostjaew, 1969; Trichostrongylus axei (Cobbold, 1879) Railliet et Henry, 1909; Trichostrongylus colubriformis Giles, 1892; Wehrdikmansia flexuosa Skrjabin, 1949; Wehrdikmansia cervipedis Skrjabin, 1949.

Из 31 обнаруженных видов паразитов 10 видов биогельминты, а 11 - геогельминты. Больше паразитирует гельминтов в желудочно-кишечном тракте, в паренхиматозных органах, в мышцах, подкожной клетчатке. По локализации отдельных видов паразитов были выявлены следующие закономерности: цистицеркозные пузыри в $81,2 \%$ случаев регистрировали на паренхиматозных органах, мышцах сердца лишь в 18,8\% при интенсивности до 9 экземпляров и до 2-х соответственно. Локализация и скопление остертагий в большей степени отмечали в сычуге $-77,7 \%$ случаев, реже в книжке и 12 -перстной кишке - 22,3\%. Трихоцефал обнаруживали в слепой кишке $57,5 \%$, в ободочной кишке - 42,5\%. Нематодирелл - 21,7\% .Личинок подкожных оводов при локализации в подкожной клетчатке спины и холки $(89,7 \%)$ при интенсивности инвазии 56-108 экз., личинки носоглоточных оводов 46,5\% интенсивность инвазии составляла32-58 экз, личинок лингватул в носовой пазухе $(10,3 \%) 2-6$ экЗ.

В естественных условиях многие инвазионные болезни животных протекают в виде смешанных инвазий. Ассоциативные гельминтозные заболевания оленей представляют большой интерес, так как без глубокого познания этих заболеваний, их специфики невозможно правильно организовать лечебно-профилактические мероприятия по борьбе с ними.

При гельминтологических исследованиях в основном отмечали смешанную инвазию двумя - пятью и более видами гель- 
минтов в теле одного животного и только в небольшом проценте отслеживали случаи моноинвазии.

При вскрытии 109 оленей регистрировали 31 ассоциацию [6], наиболее часто было отмечено паразитирование личинки носоглоточных и подкожных оводов $100 \%$, котолидоны до $26,6 \%$, парамфистомы - 10\%, дикроцелии - 0,9\%, цистицерки -3 видов от 10 до 65\%, цисты эхинококка до 10\%, нематоды: трихостронгилы- 5,5\%; трихоцефалы-2,8\%; остертагии $-14,7 \%$, нематодирусы- $1,8 \%$, нематодиреллы - 3,3\%, мезостоциркусы и диктиокаулы $-14,7 \%$, дикроцелий $-3,9 \%$ и остертагий $-5,1 \%$; встречаются в ассоциации, остальные встречались в единичных случаях, что составляет от $0,6 \%$ до $3,3 \%$. Из исследованных на ассоциации оленей у 30 голов ассоциации установлено зараженность несколькими видами паразитами - 9 видами [7-8]: Cephenomyia trompe; Cotylophoron skrjabini Mizkewitsch, 1958; Cysticercus tarandi (T. tarandu (larva) Monies, 1879); Cysticercus parenchimatosa [T. parenchimatosa (larva) Puschmenkov, 1945]; Oedemagena tarandu III cт.; Dictyocaulus eckerti Skrjabin, 1931; Trichocephalus skrjabini Baskakow, 1924; Nematodirus oiratianus Rajewskaja, 1929; Nematodirus spathiger (Railliet, 1896); 8 видами: Cephenomyia trompe; Cysticercus parenchimatosa [T. parenchimatosa (larva) Puschmenkov, 1945]; Dictyocaulus eckerti Skrjabin, 1931; Trichocephalus skrjabini Baskakow, 1924; Nematodirus oiratianus Rajewskaja, 1929; Nematodirus spathiger (Railliet, 1896); Ostertagia (G) arctica Mizkewitsch, 1929; 5 видами: Cephenomyia trompe; Cotylophoron skrjabini Mizkewitsch, 1958; Cysticercus tarandi (T. tarandu (larva) Monies, 1879); Cysticercus parenchimatosa [T. parenchimatosa (larva) Puschmenkov, 1945]; Oedemagena tarandu III ст.; 3 видами - Cephenomyia trompe; Cotylophoron skrjabini Mizkewitsch, 1958; Oedemagena tarandu III ст.

Опыты по испытанию альбена С 20\% с витаминно-минеральной добавкой проводили на 50 хорах, 210 важенках, 70 сырицам и 90 тугутам в ОПХ «Ючюгейское» Оймяконского района, 5 животных по каждой группе служили контролем. Для получения чистоты опыта $50 \%$ животных от общего поголовья были исследованы на наличие гельминтов, а затем проведена дегельминтизация препарат Альбен С комбикорм, витаминно-минеральная добавка цеолит, соль кемпендяйская, пробиотик «Сахабактисубтил», витамин Тривит.

На первом этапе работы (март-апрель) изучали поедаемость минерально-солевых подкормки с комбикормом и биопрепа- 
ратом без антигельминтого препарата, подкормку проводили в течение трех дней. Наблюдения показали хорошую поедамость смеси, рассчитали норму применения паразитоцида (альбена С $20 \%)$ в дозе лекарственного вещества.

I группа подопытных оленей, важенки: смесь задавали начиная с 20 по 24 июня минерально-солевая подкормка с витамином Тривит, пробиотик «С ахабактисубтил» 25 июня проводим лечение - подкормка с альбеном С, 26-28 июня продолжаем подкормку;

II группа подопытных оленей, сырицы: смесь задавали начиная с 20 по 24 июня минерально-солевая подкормка пробиотиком «Сахабактисубтил», 25 июня проводим лечение - подкормка с альбеном C, 26-28 июня продолжаем подкормку;

III группа подопытных оленей, тугуты: смесь задавали начиная с 20 по 24 июня минерально-солевая подкормка с пробиотиком «Сахабактисубтил», 25 июня проводим лечение - подкормка с альбеном C, 26-28 июня продолжаем подкормку;

IV группа подопытных хоры: начиная с 20 по 24 июня минерально-солевая подкормка, 25 июня проводим лечение - подкормка с альбеном C, 26-28 июня продолжаем подкормку;

V группа контрольные олени 10 гол (по 2 гол. с каждой группы) -минерально-солевая подкормка проводили без добавления антигельминтика;

VI группа контрольная группа оленей только антигельминтный препарат.

Профилактическую эффективность витаминно-минеральных добавок, с антгельминтиком определяли по данным копрологических исследований, которые проводили с интервалом 30 дней с мая по сентябрь 2014 года.

По всем группам, где задавался препарат, наблюдается снижение экстенсивности инвазии в 2 и более раза, так у хоров при элафостронгилезе ЭИ в мае составляла 25,0\%, а в сентябре - 12,5\%; у облаканов 2-х летнего возраста в мае - $100 \%$, а в сентябре - 16,7\%; экстенсивность инвазии при этом сократилась почти в 6 раз; у тугутам - экстенсивность инвазии при элафостронгилезе уменьшилась почти в 4 раза (в мае $100 \%$, в сентябре $-24,2 \%$ ), а в контроле только в 2 раза (в мае $-100 \%$, в сентябре $-50,0 \%)$. В свою очередь интенсивность инвазии в опыте при элафостронгилезе снизилась в 16 раз (с 230,6 экз/г до 14,3 экз/г), а в контроле - только в 5 раз (с 210,5 экз/г до 39,5 эКз/г). 
Результаты опытов показали, что применение противопаразитарных препаратов с минерально-солевыми, пробиотиком и витамином в весенне-летнее и осенне-зимнее время значительной степени обеспечить профилактику оленей от гельминтозов, улучшает поедаемость препарата.

Применение в весенне-летний период противопаразитарных минерально-солевых добавок с альбеном С снижается инвазированность элафостронгилами и кишечными стронгилятами на $18,5 \%$, а интенсивность инвазии не превышает $1,2-1,9$ экземпляров в 1 г фекалий.

Лечебно-профилактические мероприятия против ассоциаций возбудителей бывает сложной, трудно подобрать отвечающие требованиям средства и методы терапии и профилактики, так как паразиты отличаются своими циклами развития, локализацией, сезонностью и другими признаками.

Проведенные нами опыты в ОПХ «Ючюгейское» Оймяконского района показали, что контролировать численность наиболее вредоносных гельминтов у оленей и удерживать их на экономически безопасном уровне позволяет только трехкратная дегельминтизация животных.

Определены оптимальные сроки терапии и профилактики при ассоциативной инвазии, с применением противопаразитарных средств проводить по следующей схеме:

1. Осеннюю терапию приурочили близко к зимнему содержанию (октябрь - ноябрь), после проведение осенней подкормки, после завершение гона, важенки находятся на ранних сроках беременности, проводится отъем тугутов текущего года рождения. Заражения животных в это время не происходит, а основное количество элафостронгил, стронгилид и трихоцефал достигли III или имагинальной стадии, личинки оводов находятся на I - II стадиях развития. Обработке подлежат олени всех половозрастных групп за исключением отъемышей тугутов оставленных на зимовку, дегельминтизацию которых целесообразно проводить в декабре, после основного забоя молодняка. Более поздние сроки дегельминтизации тугутов определены общими ветеринарно-санитарными мероприятиями местной ветеринарной службы, такие как вакцинация, против бруцеллеза и особенностями биологии паразитов (в сентябре-октябре основное количество элафостронгил и стронгилид находились на ранних стадиях развития). Применение препарата на основе клозантела эффективна против нематод, трематод и личинок 
оводов. На 30 - 40 дни эффективности лечения по результатам копрологических исследований фекалий достигала 97,6-100\% в каждой половозрастной группе.

2. Избирательность действия препаратов из группы макроциклических лактонов на половозрелых гельминтов и личинок III - IV стадий и активный рост личинок желудочно-кишечных и легочных нематод определяет проведение повторной дегельминтизации в марте-апреле. Учитывая, что в этот период важенки глубоко стельные, обработку необходимо проводить по-этапно по следующей схеме:

- выборочное копрологические исследование проб фекалий от $10 \%$ от всего поголовья стада в марте и начале апреля.

- групповое скармливание антгельминтиком Альбен С в смеси с витаминно-минеральной добавкой с комбикормом в течение $3-5$ дней (апрель, июль).

3. Перед летней пастьбой от $10 \%$ животных каждой половозрастной группы исследовали материал оволарвоскопическими методами на наличие яиц и личинок гельминтов во время летней корализации, обработку оленей в этот период проводили скармливание антгельминтиком Альбен С в смеси с витаминно-минеральной добавкой с комбикормом подкормкой в специально оборудованных расколах для массовых обработок. Молодняк текущего года рождения обрабатывали в рукавах раскола по $4-8$ животных в отсеке.

Считаем такой подход экономически не целесообразным, во-первых до июля происходит контаминация пастбища, во-вторых, в летний период происходит самоотмирание основного количества имагинальных стадий гельминтов и инвазирование юными формами, против которых препараты ивермектинового ряда неэффективны и не предохраняют животных от повторного заражения.

Экономическая эффективность противопаразитарных мероприятий при применении препарата широкого спектра действия - аверсект - 2 на примере ОПХ «Ючюгейское» на 2013 год составила на каждый вложенный рубль - 6,4 рубля прибыли. Экономическая эффективность противопаразитарных мероприятий при применении препарата широкого спектра действия альбена гранулята 20\%-ного на примере ОПХ «Ючюгейское» Оймяконского района на 2014 год составила на каждый вложенный рубль - 5,6 рубля прибыли. 
Противопаразитарные обработки рекомендуемыми препаратами в указанные сроки позволяют контролировать численность наиболее вредоносных паразитов и удерживать ее на экономически безопасном уровне.

\section{ПРАКТИЧЕСКИЕ ПРЕДЛОЖЕНИЯ}

1. Для профилактики гельминтозов оленей рекомендуем применение витаминно-минерально-солевых смесей с альбеном С.

2. Также проведения осенней и весенней профилактической дегельминтизации домашних оленей при ассоциативной инвазии рекомендуем применение массы животного. 


\section{Использованная литература}

1. Беляев В.И., Назарова Н.С. Гельминты северных оленей Ненецкого автономного округа // Диагностика, профилактика и терапия болезней животных на Крайнем Севере. Новосибирск, 1983. - C.95-98.

2. Губанов Н.М. Гельминтофауна промысловых млекопитающих Якутии //Н.М. Губанов. - М., Наука, - 1964. - 70с.

3. Забродин В.А., Подкорытов Ф.М., Силков А.М. и др. Применение комбикормов-концентратов и белково-минеральной добавки в северном оленеводстве / Рекомендации. М.: Россельхозиздат, 1980. $-16 \mathrm{c}$.

4. Исаков, С.И. Гельминты и гельминтозы северных оленей Якутии. - Якутск, 1990. - 36 с.

5. Коколова Л.М. Эпизоотология ларвальных тениидозов северных оленей Якутии и меры борьбы с ними // Л.М. Коколова. /Диссерт. на соискание уч. ст. канд. вет наук. Москва. - 1995 г. - 100 с.

6. Коколова Л.М. Профилактика цистицеркозов северных оленей и меры борьбы с ними в Якутии // Л.М. Коколова. Методические рекомендации. - Якутск. $-1995 .-12 \mathrm{c}$.

7. Коколова Л.М., Григорьев И.И. Изучение гельминтозов северных оленей в горно-таежной зоне Якутии. / Л.М. Коколова, И.И. Григорьев // XVI межд. конф. «Аграрная наука сельскохозяйственного производства Сибирии» Монголия, Казахстан и Болгария. - 2013. - C. 152 .

8. Мицкевич В.Ю. Гельминты северного оленя и вызываемые ими заболевания. - Л., 1967. - 182 с.

9. Сафронов М.Г. О Гельминтофауне оленей в Томпонском и Оленекском районах Якутской АССР./ М.Г. Сафронов. Тр. Якутского НИИСХ, вып. III, Якутск, 1960.

10. Сафронов М.Г. Гельминты копытных животных Якутии. // Тр. Як. НИИСХ. - 1975,- №11. - Вып. Х1У. - С. 168-222. 


\section{СОДЕРЖАНИЕ}

1. Введение . . . . . . . . . . . . . . . . . . . . 3

2. Химиотерапевтических исследований при ассоциативных инвазиях домашних северных оленей . . . 4

3. Практические предложения. . . . . . . . . . . . . . . . 13

4. Использованная литература. . . . . . . . . . . . . . . 14 
Коколова Людмила Михайловна

Гаврильева Любовь Юрьевна

Григорьев Иннокентий Иннокентьевич

\section{МЕТОДИКА ПРИМЕНЕНИЕ АЛЬБЕНА С ПРИ ПАРАЗИТАРНЫХ БОЛЕЗНЯХ ДОМАШНИХ СЕВЕРНЫХ ОЛЕНЕЙ}

$$
\text { (методическое пособие) }
$$

Адрес: 677001, Республика Саха (Якутия)

г. Якутск, ул. Бестужево-Марлинского 23/1 тел. (4112) 21-45-74

e-mail: kokolova_lm@mail.ru, agronii@sakha.ru 
Подписано в печать 05.02.18.

Формат 60x84 /16. Усл. печ. л. 1,2. Гарнитура Таймс.

Печать цифровая. Тираж 300. Заказ №

Отпечатано с готовых диапозитивов в типографии

ООО «Компания «Дани-Алмас»

677000, Республика Саха (Якутия), г. Якутск, ул. Билибина 10А, тел/факс. 39-92-91.

e.mail: ofset_lenina@mail.ru 